\title{
On using clay and nanoclay ceramic granules in reducing lead, arsenic, nitrate, and turbidity from water
}

\author{
Parisa Rezvani ${ }^{1} \cdot$ Mohammad Mehdi Taghizadeh $^{1}$ (D)
}

Received: 8 October 2017 / Accepted: 31 July 2018 / Published online: 6 August 2018

(c) The Author(s) 2018

\begin{abstract}
New technology has provided a cheap and abundant access to nanoclay which has more prominent and efficient properties than clay. The aim of this research was a performance review of clay and nanoclay granules for the purpose of improving physicochemical as well as biological quality of water. To this end, clay granules and a 50\% composition of clay and nanoclay with an average of a 5-mm diameter were made and placed in the $1000^{\circ} \mathrm{C}$ furnace for $7 \mathrm{~h} .150 \mathrm{~g}$ of any kind of granule was put in a closed system with presence of $300 \mathrm{ml}$ of sample of synthesized contaminated water for $24 \mathrm{~h}$. Then, heavy metals (lead and arsenic), anions (nitrate), turbidity, electrical conductivity and microbial contamination (coliforms) were measured. The clay and nanoclay granules had adsorbed the lead, respectively, with $0 / 4$ and $/ 44 \mathrm{mg} / \mathrm{l}$ by $80 \%$ and $88 \%$ yield. They have been almost effective in declining nitrate, arsenic, turbidity, and electrical conductivity, though ineffective in removal of microbial contamination. The results show that the adsorption yield for nanoclay is much higher than that for clay.
\end{abstract}

Keywords Clay $\cdot$ Nanoclay $\cdot$ Water treatment $\cdot$ Ceramic $\cdot$ Arsenic

\section{Introduction}

The spread of water pollution to heavy metals, dangerous anions, microbial and physical contaminations make the knowledge of water treatment a necessary issue. Adsorption is the adhesion of atoms, ions or molecules from a gas, liquid or dissolved solid to a surface. The absorbents are among the varied effective materials having satisfactory results in removing contaminants from water (Makhado et al. 2018, 2017).

Numerous researches have been done for usability of inexpensive and aboriginal adsorbents such as activated carbon prepared by pistachio, walnut and almond shells (Taghizadeh and vahdati 2015), peach stones (Attia et al. 2008), bagasse (Valix et al. 2004), pecan shell (Guoans and Rockstraw 2007), almond shells (Toles et al. 2000), rice husk (Chuah et al. 2005), waste tea (Yagmur et al. 2008), corncobs (Hendawy et al. 2001), cotton-seed (Pütün et al. 2006), olive stones (El-Sheikh et al. 2004), sawdust (Rafatullah 2009), coconut shells (Azevedo et al. 2007), nutshells

Mohammad Mehdi Taghizadeh

tgmehdi@yahoo.com

1 Islamic Azad University, Estahban Branch-Fars, Estahban, Iran
(Arjmand 2006), bamboo scaffolding (Cheung et al. 2006), grape seeds (Al Bahri et al. 2012), banana stalk (Bello et al. 2012a), spent tea leaves (Hameed 2009), ginger waste (Ahmad and Kumar 2010), degreased coffee bean (Baek et al. 2010).

However, most of the introduced adsorbents are efficient in qualitative improvement in water in special conditions such as acidic or alkaline $\mathrm{pH}$, high temperatures, or in smaller dimensions. Some of the adsorbents, especially ashes, are dissolved in water, making their removal much difficult. Various investigations about using natural clay and its composites in removal of biological, organic and inorganic contaminants from drinking water show a unique functionality as well as simple applications of these materials (Srinivasan 2011). A study of the effect of clay on water quality together with fluoride adsorption using clay granules was done, where it was shown that clay granules had adsorbed up to $95 \%$ of fluoride, depending on the $\mathrm{pH}$ concentration and on the presence of interfering ions (Chen et al. 2010).

Although very small dimensions of clay have proved to be good adsorbents, particle dispersion in water has made the practical use difficult. Adeyemo (2017) has suggested that granulation of clay adsorbents in baked form which is used before may resolve the problem. On the other hand, noteworthy developments in nanotechnology have offered 
a novel material called nanoclay shedding light on various applied fields such as environment as well as water and sewage treatment.

Nanoclays contain small and irregular plates of nearly $1 \mathrm{~m}$ width and $100 \mathrm{~nm}$ diameter. Enclosing a $750 \mathrm{~m}^{2} / \mathrm{g}$ of specific surface causes the nanoclays to have manifold efficiencies with a remarkable increase in the features compared with natural clay.

Different studies have, as yet, explored the application of clay or nanoclay along with colanders, ceramic filters, clay pipes, or earthen containers. The nanoclays with very small sizes have been of desirable efficiencies in adsorption of both organic and heavy metals (Prachi 2013; Pandey 2017; Pandey and Ramontja 2016a, b).

Recently, the usage of self-assembled adsorbent nanocomposites has shown acceptable results in water and wastewater treatment (Guo et al. 2015; Zhao et al. 2017; Xing et al. 2017).

Having active agents of carboxyl, hydroxyl and amide, organic materials form a chemical bond with CNT level being the electron donor (Pan and Xing 2008). CNT has a higher absorption property than carbon (Rao et al. 2007; Yang et al. 2008; Li et al. 2004). The nano-size scale metals such as iron oxides, titanium oxides and aluminum oxides are among efficient and economical adsorbents to remove heavy metals and radioactive materials (Mayo et al. 2007; Deliyanni et al. 2003; Lu et al. 2006). Nanopolymer materials are effective in removal of both organic and heavy metals (Diallo et al. 2005; Pandey 2017; Pandey and Ramontja 2016a, b). Nonetheless, the main practical problem in dealing with nanoparticles is the costly methods of their removal from water. Besides high costs of repeating usage, their residues in water may be conducive to dangerous effects on human health and the environment (Rejinders 2006). Hence, in this research, clay nanoparticles are used innovatively to make clay granules and compare them with ordinary granules. Owing to the perils of lead and arsenic in water resources, certain heavy metals are used in this feasibility study to remove lead and arsenic. If the output of the removal is efficient, other heavy metals also may be put under study.

In this research, we study the possibility to remove lead and arsenic from heavy metals using the granules and nanogranules of the baked clay.

Being heavy metals as well as cumulative poisons, lead and arsenic have risks to health. For instance, lead affects body systems such as nervous, blood, digestive, heart, and kidney systems (WHO 2010). Similarly, arsenic is known to be carcinogen to human so that long-term contacts with it may bring about diabetes and cardiovascular as well as neurological diseases (WHO 2012). The acceptable limits for arsenic and lead in drinking water are determined, respectively, as $0.01 \mathrm{mg} / \mathrm{l}$ and $0.015 \mathrm{mg} / \mathrm{l}$ (USEPA 2011).
Due to the scale of dispersion of nitrate in water resources, particularly in Iran, the feasibility of nitrate removal by granules is also studied in this article. The effect of the granules on reduction of coliforms and probable adsorption of water turbidity are the other issues under investigation in this research. Since the main goal was the practical treatment in the natural conditions of water, modified conventional terms such as $\mathrm{pH}$ and temperature are avoided.

\section{Methods and materials}

The clay used in this research was provided from clay mines of Lalejin, Hamedan. Most of clay mines in Iran rest in Lalejin, and the soil of this region is of greatest quality and purity. The clay soil became homogeneous by hand grinder and the \#100 sieve to give its particles a size of less than $150 \mu \mathrm{m}$. According to the traditional instruction of making clay mud as well as the researches done, $1 \mathrm{~kg}$ of this clay was mixed with an adequate amount of water, and then $24 \mathrm{~h}$ was prescribed for water to influence the clay particles contexture, yielding higher adhesion via the hydrated particles. The resulting mixture was well kneaded, and then, soft clay was added to it till become shapeable. The prepared clay mud was hand-made in the form of granules with an average diameter of $5 \mathrm{~mm}$. The granules were situated on their surfaces in the ambient temperature for 5 days in single layers to become entirely dry (Fig. 1).

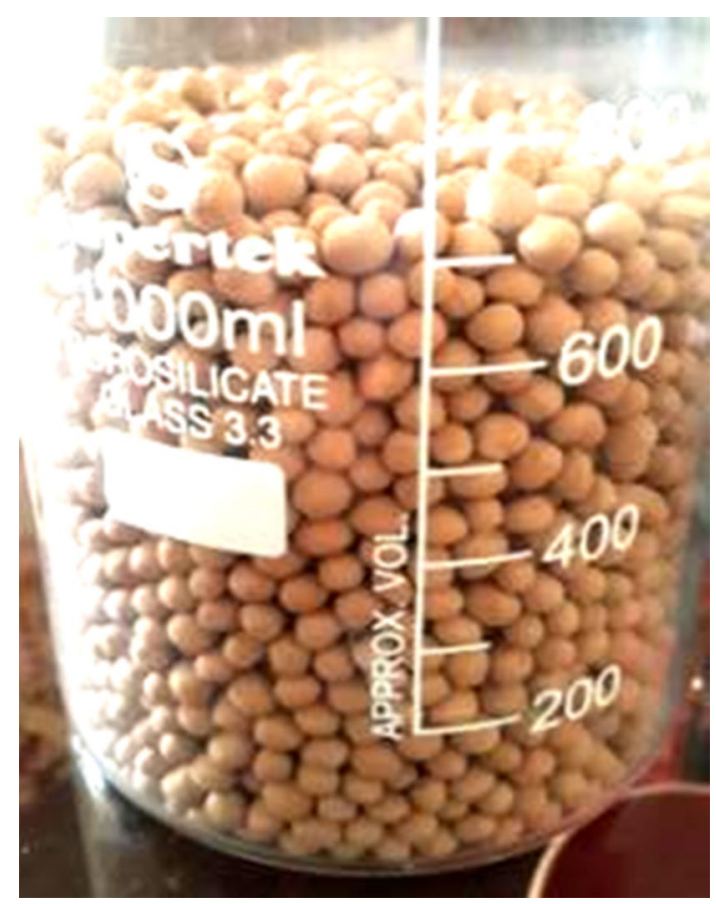

Fig. 1 Clay granules after drying 
The required nanoclay powder was prepared in montmorillonite type with degree of purity $95 \%$ and diameter of nanoparticles less than $20 \mathrm{~mm}$. To provide nanoclay granules, first the same method was applied which was used as to clay, but due to the lack of adhesion between the particles, and deficiency of necessary solidity in the granules, addition of a certain basic material to create adhesion between the nanoparticles was indispensable. So, in accordance with the goal of our experiment, clay was chosen as the basic material, and the one-to-one mix ratio of these two materials was adopted to make the desired mud.

Any clay-made structure would break down quickly in contact with water and would turn into the initial clay mud. Therefore, to maintain solidarity, the granules were put in the electric furnace at $1000{ }^{\circ} \mathrm{C}$ for $7 \mathrm{~h}$ to become "baked" and durable (EPA2004).

The contaminated water sample was prepared in laboratory according to the specifications in Table 1 considering the usual limits of water resources contamination.

To make turbidity, there were used of river bed sediments. Lead acetate solution was employed to add the lead. Also sodium arsenite was used to increase the amount of arsenic, and potassium nitrate in order to increase that of nitrate.

Table 1 Prepared water characteristics compared to acceptable limits and desired limit standards (WHO)

\begin{tabular}{llll}
\hline $\begin{array}{l}\text { Contaminated } \\
\text { water sample }\end{array}$ & Acceptable limits & Desired limits & Parameters \\
\hline $6 / 5-8 / 5$ & $6 / 5-9$ & $6 / 5-8 / 5$ & $\mathrm{pH}$ \\
$0 / 5 \mathrm{ppm}$ & $01 / 0 \mathrm{ppm}$ & 0 & Lead \\
$5 \mathrm{ppm}$ & $01 / 0 \mathrm{ppm}$ & 0 & Arsenic \\
Counting & 0 & 0 & Coliforms \\
$40 \mathrm{NTU}$ & $<5 \mathrm{NTU}$ & $<1 \mathrm{NTU}$ & Turbidity \\
$100 \mathrm{ppm}$ & $50 \mathrm{ppm}$ & 0 & Nitrate \\
\hline
\end{tabular}

$150 \mathrm{~g}$ of each kind of granules was scaled, and taking necessary water for the experiments into account, and by considering the porosity of the granules and permeability of water into them, $300 \mathrm{ml}$ of synthesized water was assigned for each sample. The third beaker with $300 \mathrm{ml}$ of water was considered as a control (Fig. 2).

A 24-h retention time was allocated to these samples during which each sample was mixed up by means of a separate stirrer till the granules and water remain much more in contact with each other. Concentration of nitrate was measured according to the standard method using a Hach Odyssey DR/2500 Spectrophotometer. Turbidity was gauged by means of the Hach measuring apparatus. Also, the arsenic and the lead were measured through the atomic absorption instrument.

\section{Results and discussion}

Table 2 shows the physical attributes of the granules such as weight, volume, density, and porosity of clay and nanoclay granules.

As seen, the nanogranules possess lesser density and greater porosity compared with the clay granules.

Table 2 Comparison of physical features between clay and nanoclay granules

\begin{tabular}{lll}
\hline Nanoclay & Clay & Granule type \\
\hline $12 / 0$ & $21 / 0$ & Average weight $(\mathrm{g})$ \\
$066 / 0$ & $066 / 0$ & Volume $\left(\mathrm{cm}^{3}\right)$ \\
$82 / 1$ & $18 / 3$ & Density $\left(\mathrm{g} / \mathrm{cm}^{3}\right)$ \\
$76 / 26$ & $87 / 18$ & Weight loss (percent) \\
$28 / 14$ & 10 & Porosity (percent) \\
\hline
\end{tabular}

Fig. 2 Beakers containing $300 \mathrm{ml}$ of sample water and granules

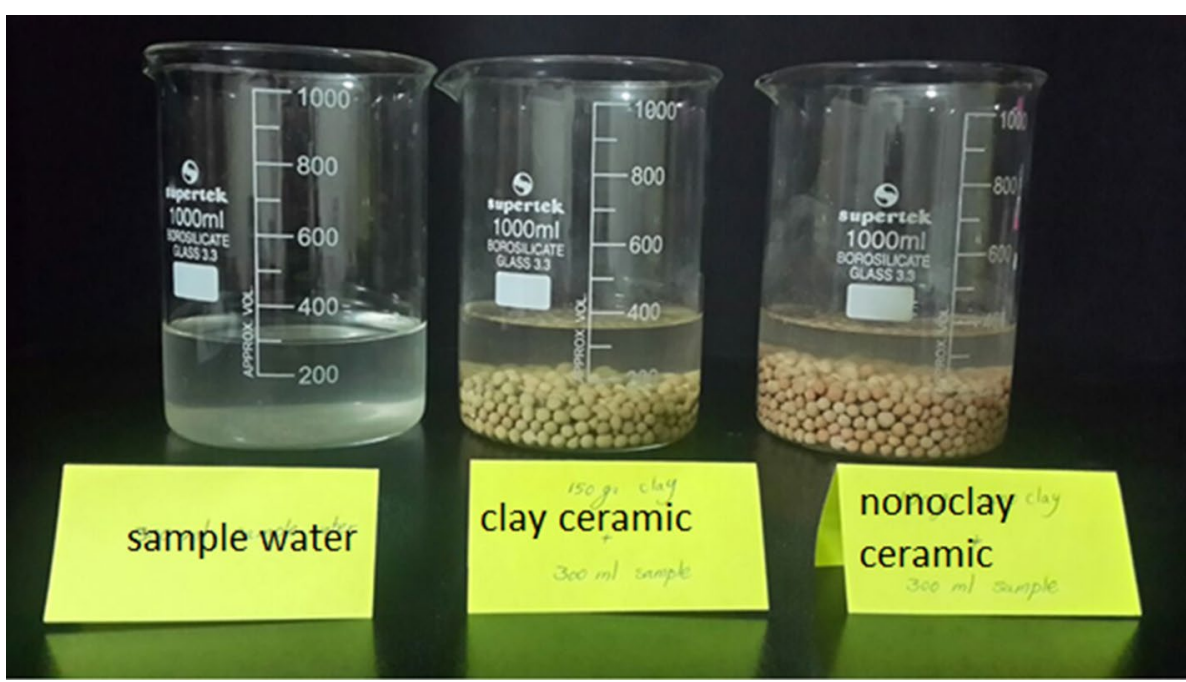

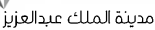

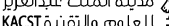


Fig. 3 Comparing the treatment efficiency of clay and nanoclay

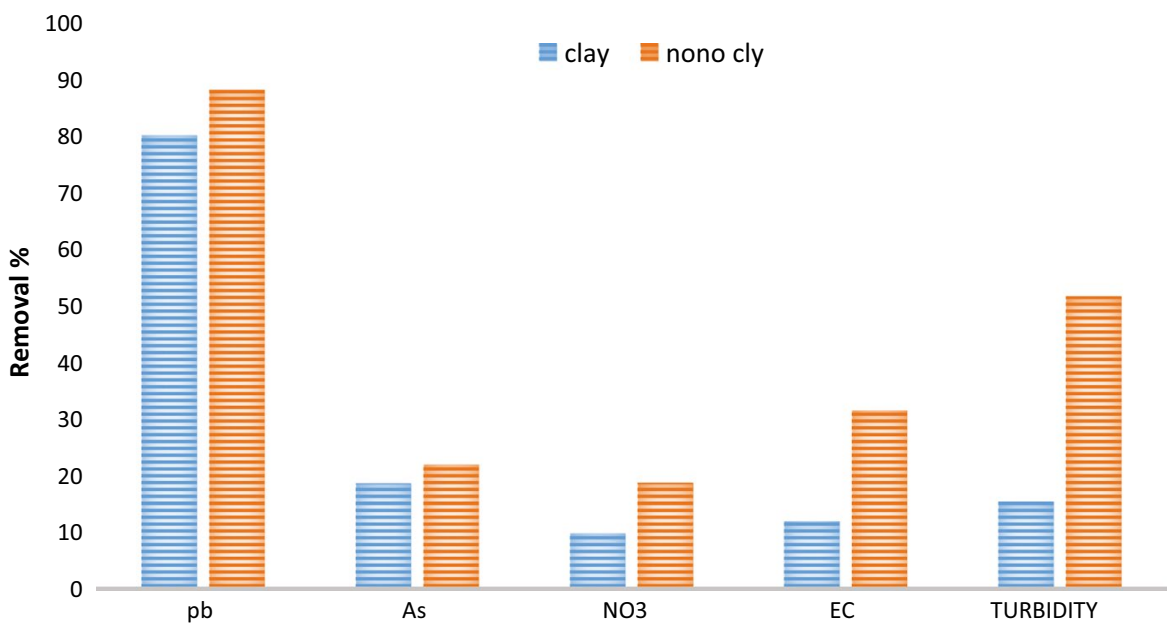

Figure 3 illustrates the $80 \%$ efficiency of the clay granules as well as the $88 \%$ efficiency resulted from the lead removal from water in the nanoclay granules. It also shows that the clay granules have $18 \%$ efficiency in removal of arsenic, while the nano clay granules contribute $22 \%$ in this regard. As observed in the figure, the clay granules have no tendency to absorb nitrate ion, which may be due to the negative charge of nitrate. However, as it is seen in the figure, absorption in the nanogranules has occurred better (though with low percentage due to adsorption) than in the clay granules.

As for electrical conductivity, Fig. 3 shows that the nanoclay granules could have reduced $31 \%$ of electrical conductivity along with water salts, whereas that of the clay granules has been $16 \%$. The decrease in turbidity by the clay granules has been $14.5 \%$, while the nanoclay granules furnish a $48 \%$ efficiency in turbidity removal, a much more appropriate absorption. After counting the coliforms, it was established that neither of granules have any effects on the cutback of the number of coliforms.

Clay and organic matters develop a characterization in the soil named as cation exchange capacity (CEC), which is a capacity the soil possesses to retain cations (generally $\mathrm{Al} 3, \mathrm{Ca}^{2+}, \mathrm{Mg}^{2+}, \mathrm{Mn}^{2+}, \mathrm{Zn}^{2+}, \mathrm{Cu}^{2+}, \mathrm{Fe}^{2+}, \mathrm{Na}+, \mathrm{K}+$ and $\mathrm{H}+$ ) (Uddin 2008) and which is characterized by the value of the positive charge of the ions retained by the negative charge of the clay materials surfaces. Therefore, the high percentage of the lead elimination as well as the low rate of nitrate and arsenic removal is justifiable. Because of having greater surfaces, the nanoparticles have been more successful in absorbing the colloidal particles. In this research, only the feasibility of the use of clay and nanoclay was studied, surely in the meantime, the interfering and effect of the other ions existing in the solution may be conducive to taking the granular absorption capacity. FTIR, XRD, SEM, TEM, zeta potential examinations can be used in finding adoption mechanisms. Examinations of FTIR, XRD, SEX, TEM and zeta potential which are not pondered in this study could be carried out to scrutinize adsorption mechanism.

\section{Conclusion}

The present research has shown that there is a possibility of applying clay and nanoclay as natural adsorbents in the form of baked granules in water treatment.

The nanoclay granules have more ion exchange capacity in comparison with the clay type. Moreover, though $50 \%$ of their weight is composed of normal clay, their efficiency in removal of the contaminants under experiment is significantly more than that for clay.

Using clay/nanoclay granules could not be so effective in reduction of coliforms as well as in improvement in biological features of water. The influence of clay granules on lessening of water nitrate has not been so remarkable. So, it is predictable that the same slight amount of reduction happens to the other anions. The cation of the heavy metals, compared with the anions, has been of more contribution to be absorbed by clay and nanoclay. It is expected that the use of clay as an adsorbent plays a key role in reduction of heavy metals such as lead, cadmium, mercury, copper and types of bivalent heavy metals. Notable reduction of these contaminants could justify the vast use of earthenware jugs in improving water quality. The present research also demonstrates the nanoparticles technology to update and improve the performance of clay adsorbents utilization.

Open Access This article is distributed under the terms of the Creative Commons Attribution 4.0 International License (http://creativeco mmons.org/licenses/by/4.0/), which permits unrestricted use, distribution, and reproduction in any medium, provided you give appropriate credit to the original author(s) and the source, provide a link to the Creative Commons license, and indicate if changes were made. 


\section{References}

Adeyemo AA, Adeoye IO, Bello OS (2017) Adsorption of dyes using different types of clay: a review. Appl Water Sci 7(2):543-568

Ahmad R, Kumar R (2010) Adsorption studies of hazardous malachite green onto treated ginger waste. J Environ Manag 91:1032-1038

Al Bahri M, Calvo L, Gilarranz MA, Rodriguez JJ (2012) Activated carbon from grape seeds upon chemical activation with phosphoric acid: application to the adsorption of diuron from water. Chem Eng J 203:348-356

Arjmand C, Kaghazchi T, Latifi SM, Soleimani M (2006) Chemical production of activated carbon from nutshells and date stones. Chem Eng Technol 29(8):986-991

Attia Girgis BS, Role F (2008) Removal of methylene blue by carbons derived from peach stones by $\mathrm{H}_{3} \mathrm{PO}_{4}$ activation: batch and column studies. Dyes Pigments 76:282-289

Azevedo DCS, Araujo JCS, Cavalcante CL (2007) Micro porous activated carbon prepared from coconut shells using chemical activation with zinc chloride. Micro Porous Meso Porous Mater 100(1):361-364

Baek MH, Ijagbemi CO, Oh SJ, Kim DS (2010) Removal of malachite green from aqueous solution using degreased coffee bean. J Hazard Mater 176:820-828

Bello OS, Ahmad MA (2012) Coconut (Cocos nucifera) shell based activated carbon for the removal of malachite green dye from aqueous solutions. Sep Sci Technol 47:903-912

Chen N, Zhang Z, Feng C, Sugiura N, Li M, Chen R (2010) Fluoride removal from water by granular ceramic adsorption. J Colloid Interface Sci 348:579-584

Cheung WH (2006) Production of high surface area activated carbons from waste Bamboo scaffolding. Hong Kong University of Science and Technology, Kowloon

Chuah TG, Jumasiah A, Azni I, Katayon S (2005) Rice husk as a potentially low-cost biosorbent for heavy metal and dye removal: an overview. Desalination 305-316

Deliyanni EA, Bakoyannakis DN, Zouboulis AI, Matis KA (2003) Sorption of $\mathrm{As}[\mathrm{V}]$ ions by akaganeite-type nano crystals. Chemosphere 50(1):155-163

Diallo MS, Christie S, Swaminathan P, Johnson JH, Goddard WA (2005) Dendrimer enhanced ultrafiltration. 1. Recovery of $\mathrm{Cu}$ [II] from aqueous solutions using PAMAM dendrimers with ethylene diamine core and terminal NH2 groups. Environ Sci Technol 39(5):1366-1377

El-Sheikh AH, Newman AP, Al-Daffaee HK, Phull S, Cresswell N (2004) Characterization of activated carbon prepared from a single cultivar of Jordanian Olive stones by chemical and physicochemical techniques. J Anal Appl Pyrolysis 71:151-164

Guo H, Jiao T, Zhang Q, Guo W, Peng Q, Yan X (2015) Preparation of graphene oxide-based hydrogels as efficient dye adsorbents for wastewater treatment. Nanoscale Res Lett 201510:272. https://doi. org/10.1186/s11671-015-0931-2

Guoans Y, Rockstraw A (2007) Physicochemical properties of carbons prepared from pecan shell by phosphoric acid activation. Bio Resour Technol 98(8):1513-1521

Hameed BH (2009) Spent tea leaves: a new non-conventional and lowcost adsorbent for removal of basic dye from aqueous solutions. $\mathbf{J}$ Hazard Mater 161:753-759

Hendawy EL, Samara SE, Girgis BS (2001) Adsorption characteristics of activated carbons obtained from corncobs. Colloids Surf A Physicochem Eng Aspects 180(3):209-221

Li YH, Ding J, Luan ZK, Di ZC, Zhu YF, Xu CL, Wu DH, Wei BQ (2004) Competitive adsorption of $\mathrm{Pb} 2 p, \mathrm{Cu} 2 \mathrm{p}$ and $\mathrm{Cd} 2 \mathrm{p}$ ions from aqueous solutions by multiwall carbon nanotubes. Carbon 41(14):2787-2792
Lu CS, Chiu H, Liu CT (2006) Removal of zinc[II] from aqueous solution by purified carbon nanotubes: kinetics and equilibrium studies. Ind Eng Chem Res 45(8):2850-2855

Makhado E, Pandey S, Nomngongo PN, Ramontja J (2017) Fast microwave-assisted green synthesis of xanthan gum grafted acrylic acid for enhanced methylene blue dye removal from aqueous solution. Carbohydr Polym 176:315-326

Makhado E, Pandey S, Nomngongo PN, Ramontja J (2018) Preparation and characterization of xanthan gum-cl-poly(acrylic acid)/oMWCNTs hydrogel nanocomposite as highly effective re-usable adsorbent for removal of methylene blue from aqueous solutions. J Colloid Interface Sci 513:700-714

Mayo JT, Yavuz C, Yean S, Cong L, Shipley H, Yu W, Falkner J, Kan A, Tomson M, Colvin VL (2007) The effect of nano crystalline magnetite size on arsenic removal. Sci Technol Adv Mater $8(1-2): 71-75$

Pan B, Xing BS (2008) Adsorption mechanisms of organic chemicals on carbon nanotubes. Environ Sci Technol 42:9005-9013

Pandey S (2017) A comprehensive review on recent developments in bentonite-based materials used as adsorbents for wastewater treatment. J Mol Liq 241:1091-1113. https://doi.org/10.1016/j.molli q.2017.06.115

Pandey S, Ramontja J (2016a) Turning to nanotechnology for water pollution control: applications of nanocomposites. Focus Sci 2(2):1-10. https://doi.org/10.20286/focsci-020219

Pandey S, Ramontja J (2016b) Natural bentonite clay and its composites for dye removal: current state and future potential. Am J Chem Appl 3(2):8-19

Prachi P, Gautam D, Madathil NA (2013) Nanotechnology in waste water treatment: a review. Int J Chem Tech Res 5:2303-2308

Pütün E, Uzun BB, Pütün AE (2006) Fixed-bed catalytic pyrolysis of cotton-seed cake: Effects of pyrolysis temperature, natural zeolite content and sweeping gas flow rate. Bio Resour Technol 701-710

Rafatullah M (2009) Adsorption of copper(II), chromium(III), nickel(II) and lead(II) ions from aqueous solutions by meranti sawdust. J Hazard Mater 969-97

Rao GP, Lu C, Su F (2007) Sorption of divalent metal ions from aqueous solution by carbon nanotubes: a review. Sep Purif Technol 58(1):224-231

Reijnders L (2006) Cleaner nanotechnology and hazard reduction. J Clean Prod 14:124-133

Srinivasan R (2011) Advances in application of natural clay and its composites in removal of biological, organic, and inorganic contaminants from drinking water. Adv Mater Sci Eng Volume 2011, Article ID 872531, p 17

Taghizadeh MM, Vahdati R (2015) Study about efficiency of nitrate removal from water by activated carbon prepared by pistachio, walnut and almond shells. Int J Biosci 6(2):375-379

Toles CA, Marshall WE, Wartelle LH, Johns MM (2000) Acid activated carbons from almond shells: physical, chemical and adsorptive properties and estimated cost of production. Bio Resour Technol 87-92

Uddin F (2008) Clays, nano clays, and montmorillonite minerals. Metall Mater Trans 39:2804-2814. https://doi.org/10.1007/s1166 1-008-9603-5

U.S. EPA (2011) Exposure factors handbook: 2011 edition. National Center for Environmental Assessment, Washington, DC, U.S. EPA Office of Research and Development. EPA/600/R-090/052F. https://cfpub.epa.gov/ncea/risk/recordisplay.cfm?deid=236252. Accessed 13 July 2017

Valix M, Cheung WH, Kay GM (2004) Preparation of activated carbon using low temperature carbonization and physical activation of high ash raw bagasse for acid dye adsorption. Chemosphere 493-501

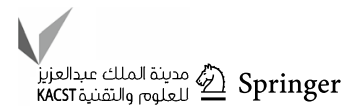


WHO (2010) Preventing disease through healthy environments exposure to lead: a major public health. www.who.int/ipcs/features/ lead.pdf

WHO (2012) International Agency for Research on Cancer. Arsenic, metals, fibres and dusts. A review of human carcinogens. International Agency for Research on Cancer, World Health Organisation: Geneva, Switzerland, World Health Organization's Arsenic Fact Sheet. 2016. Available online: http://www.who.int/media centre/factsheets/fs372/en/. Accessed 15 Jan 2017

Xing R, Wang W, Jiao T, Ma K, Zhang Q, Hong W, Qiu H, Zhou J, Zhang L, Peng Q (2017) bioinspired polydopamine sheathed nanofibers containing carboxylate graphene oxide nanosheet for high-efficient dyes scavenger. ACS Sustain Chem Eng 5(6):49484956. https://doi.org/10.1021/acssuschemeng.7b00343

Yagmur E, Ozmak M, Aktas Z (2008) A novel method for production of activated carbon from waste tea by chemical activation with microwave energy. Fuel 3278-3285
Yang K, Wu WH, Jing QF, Zhu LZ (2008) Aqueous adsorption of aniline, phenol, and their substitutes by multi-walled carbon nanotubes. Environ Sci Technol 42:7931-7936

Zhao X, Ma K, Jiao T, Xing R, Ma X, HU J, Huang H, Zhang L, Yan X (2017) Fabrication of hierarchical layer-by-layer assembled diamond-based core-shell nanocomposites as highly efficient dye absorbents for wastewater treatment. Sci Rep 7:44076. https://doi. org/10.1038/srep44076

Publisher's Note Springer Nature remains neutral with regard to jurisdictional claims in published maps and institutional affiliations. 